ARTICLE

\title{
Chemical States of Fission Products and Actinides in Irradiated Oxide Fuels Analyzed by Thermodynamic Calculation and Post-Irradiation Examination
}

\author{
Ken KUROSAKI ${ }^{1, *}$, Kosuke TANAKA ${ }^{2}$, Masahiko OSAKA ${ }^{3}$, Yuji OHISHI ${ }^{1}$, \\ Hiroaki MUTA ${ }^{1}$, Masayoshi $\mathrm{UNO}^{3}$ and Shinsuke YAMANAKA ${ }^{1,3}$ \\ ${ }^{1}$ Osaka University, 2-1 Yamdaoka, Suita, Osaka 565-0871, Japan \\ 2 Japan Atomic Energy Agency, Narita-cho 4002, Oarai-machi, Higashiibaraki-gun, Ibaraki, 311-1393, Japan \\ ${ }^{3}$ University of Fukui, 3-9-1 Bunkyo, Fukui 910-8507, Japan
}

\begin{abstract}
It is important to understand the behavior of fission products and actinides under irradiation. In the present study, the chemical states of fission products and actinides in irradiated oxide fuels were evaluated by both thermodynamic equilibrium calculation and post-irradiation examination.
\end{abstract}

KEYWORDS: oxide fuel, fission product, actinide, thermodynamic calculation, post-irradiation examination

\section{Introduction}

In irradiated oxide fuels, a number of fission products (FPs) and actinides are produced. They take various chemical states depending on the conditions of the fuel, e.g. temperature and oxygen potential. ${ }^{1,2)}$ The compounds composed of FPs and actinides would affect significantly the fuel characteristics. Therefore, the behavior of FPs and actinides under irradiation and the properties of their compounds are very important for evaluation of the fuel performance. It has been recognized that some FPs such as lanthanides $(\mathrm{Ln})$ are soluble in the fuel matrix and form solid solutions of $(\mathrm{U}, \mathrm{Pu}, \mathrm{Ln}) \mathrm{O}_{2}$. On the other hand, some FPs such as alkaline and alkaline-earth elements, molybdenum, and platinum-family metals form oxides or metallic inclusions such as Mo-Tc-Ru-Rh-Pd alloys, (Ba,Sr) $(\mathrm{U}, \mathrm{Zr}, \mathrm{Mo}) \mathrm{O}_{3}$, and $\mathrm{Cs}_{2}(\mathrm{Mo}, \mathrm{U}) \mathrm{O}_{4}$, etc. However, there exist still many points that are doubtful and unclear with regard to the behavior of FPs and actinides under irradiation. In the present study, we tried to evaluate the chemical states of FPs and actinides in irradiated oxide fuels by both thermodynamic equilibrium calculation and post-irradiation examination (PIE). The calculated results were compared with the PIE results.

\section{Thermodynamic Calculation}

The thermodynamic equilibrium calculation program, ChemSage, ${ }^{3)}$ was applied to estimate the chemical states of FPs in an irradiated oxide fuel. The ChemSage program was utilized to obtain the equilibrium state of the multicomponent and multiphase system finding the minimum of the total free energy of the system. The stoichiometric $\left(\mathrm{U}_{0.8} \mathrm{Pu}_{0.2}\right) \mathrm{O}_{2}$ was taken as a loading fuel. The ORIGEN-2 code ${ }^{4)}$ was used to calculate the FP inventories. In the present study, the $20 \%$

*Corresponding author, E-mail:kurosaki@see.eng.osaka-u.ac.jp

(c) 2011 Atomic Energy Society of Japan, All Rights Reserved.
Pu-containing mixed oxide was used as the fuel, in which natural uranium was loaded. The Pu isotope ratio was preliminary calculated based on a spent fuel of LWR for $55 \mathrm{GWd}$ with 5 years of cooling time. The burnup was $100 \mathrm{GWd} / \mathrm{t}$, and the calculation was performed under a fast reactor circumstance for the irradiation conditions.

In order to evaluate the effect of oxygen potential on the phase equilibria of the fuel, the oxygen potential was varied from -500 to $-200 \mathrm{~kJ} / \mathrm{mol}$. Although there exists temperature gradient in the fuel pellet under irradiation, we performed the thermodynamic calculation at $1273 \mathrm{~K}$.

In the present study, ten FPs were selected for the representative elements of all major FPs, except for the volatile elements. This classification was referred to the previous study reported by Lucuta et al. ${ }^{5)}$ In this case, the FP elements with similar chemical behavior were represented by a single element. Note that the amounts of the representative elements are summation of that of each FP of the group.

The gas phase, matrix phase, oxide precipitate, metallic precipitate, and other solid phase were selected in the present calculation. The gas phase consists of single elements and oxides as an ideal gas. The matrix phase $\left(\mathrm{MO}_{2}\right)$ consists of $\mathrm{UO}_{2}, \mathrm{PuO}_{2}, \mathrm{ZrO}_{2}, \mathrm{Y}_{2} \mathrm{O}_{3}, \mathrm{La}_{2} \mathrm{O}_{3}, \mathrm{CeO}_{2}$, and $\mathrm{Nd}_{2} \mathrm{O}_{3}$ as an ideal solution. Assuming that the oxide precipitate exists as two kinds of chemical form, the first one is $\mathrm{BaMO}_{3}(M: \mathrm{U}, \mathrm{Zr}$, Mo) type and the other is $\mathrm{BaMO}_{4}(\mathrm{M}: \mathrm{U}, \mathrm{Mo})$ type. The metallic precipitate is also assumed to exist as two kinds of chemical form, Mo-Me (Me: $\mathrm{Ru}, \mathrm{Rh}, \mathrm{Pd})$ alloy and $\mathrm{UMe}_{3}$ (Me: Ru, Rh, Pd) type intermetallic compound. Other solid phases are assumed to exist as single elements, oxides, and intermetallic compounds.

Summary of the present calculation is shown in Table 1. It was found that the $\mathrm{MO}_{2}$ phase that corresponds to the fuel matrix phase and Mo-Me alloy were always stable under the whole conditions. The $\mathrm{BaMO}_{3}$ phase which corresponds to 
Table 1 Chemical states of FPs calculated in the present study

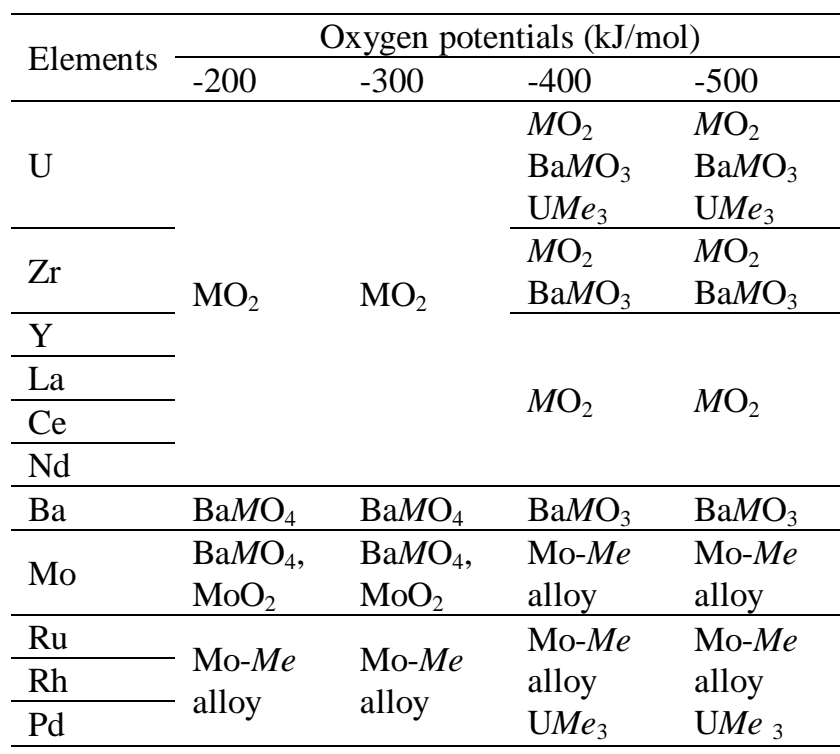
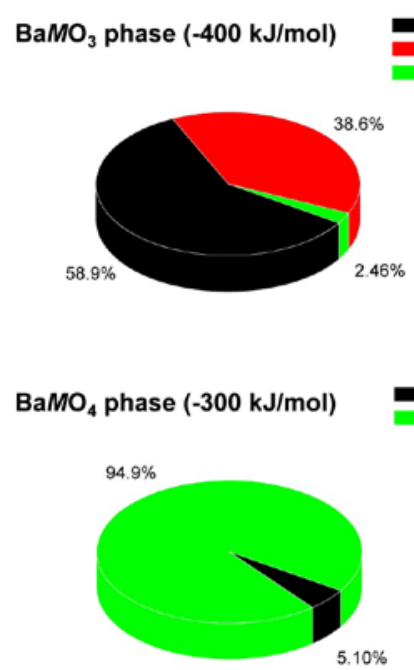

Fig. 1 Compositions of the $\mathrm{BaMO}_{3}(\mathrm{M}: \mathrm{U}, \mathrm{Zr}, \mathrm{Mo})$ phase and $\mathrm{BaMO}_{4}(M: \mathrm{U}, \mathrm{Mo})$ phase

the gray oxide phase did not exist as a stable phase under high oxygen potentials, because $\mathrm{MoO}_{2}$ and $\mathrm{BaMO}_{4}$ phase were stable chemical species in these conditions. At low oxygen potentials, the $\mathrm{UMe}_{3}$ type intermetallic compound was stable in addition to the Mo-Me alloy as the metallic precipitate.

Figure 1 shows the compositions of the $\mathrm{BaMO}_{3}(M: \mathrm{U}, \mathrm{Zr}$, Mo) phase and $\mathrm{BaMO}_{4}(M: \mathrm{U}, \mathrm{Mo})$ phase under the oxygen potentials of -300 and $-400 \mathrm{~kJ} / \mathrm{mol}$. $\mathrm{BaMO}_{3}$ phase was stable under the low oxygen potentials ( -500 and $-400 \mathrm{~kJ} / \mathrm{mol}$ ) and the $\mathrm{BaMO}_{4}$ phase was stable under the high oxygen potentials (-300 and $-200 \mathrm{~kJ} / \mathrm{mol})$. $\mathrm{BaMO}_{3}$ phase was composed of $58.9 \%-\mathrm{BaUO}_{3}, 38.6 \%-\mathrm{BaZrO}_{3}$, and $2.5 \%-\mathrm{BaMoO}_{3}$. $\mathrm{BaMO}_{4}$ phase was composed of $94.9 \%-\mathrm{BaMoO}_{4}$ and $5.1 \%-\mathrm{BaUO}_{4}$.

As described before, the metallic precipitate in the irradiated oxide fuels consists of Mo, Tc, and the platinum family metals (Me: $\mathrm{Ru}, \mathrm{Rh}, \mathrm{Pd})$. The compositions of the
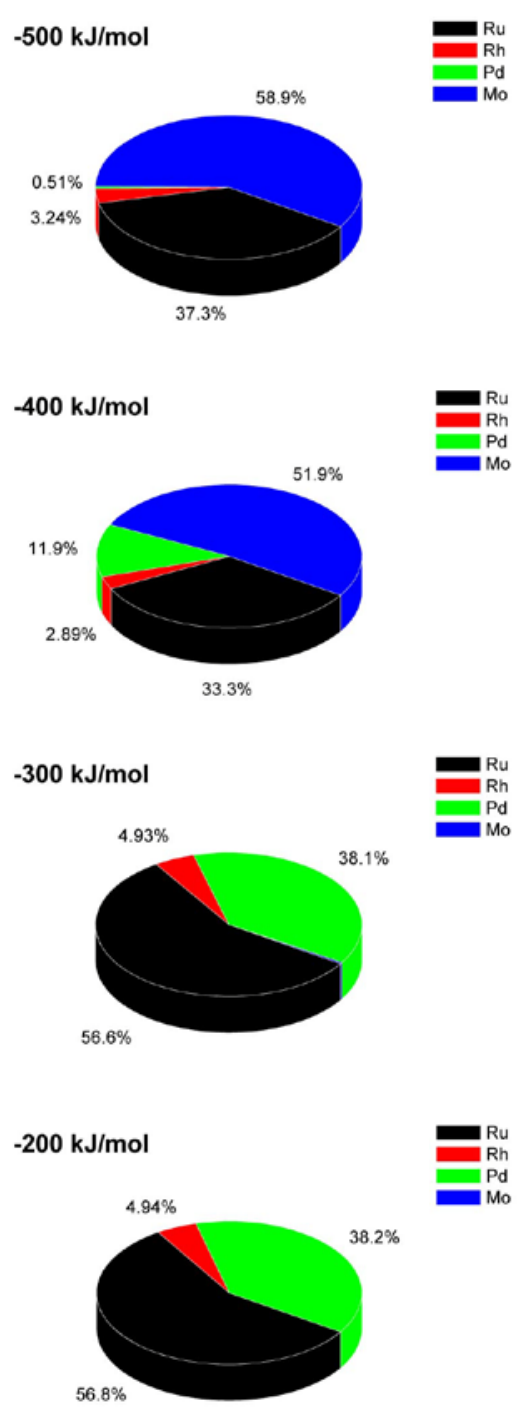

Fig. 2 Compositions of the Mo-Me (Me: Ru, Rh, Pd) alloy under various oxygen potentials

Mo-Me alloy under the various oxygen potentials are shown in Fig. 2. Mo was scarcely contained in the Mo-Me alloy under the high oxygen potentials because Mo was stable as $\mathrm{MoO}_{2}$ or $\mathrm{BaMoO}_{4}$ under the high oxygen potentials. On the other hand, under the oxygen potential of $-500 \mathrm{~kJ} / \mathrm{mol}$, no Pd existed in the Mo-Me alloy, because Pd was stable as U-Me type intermetallic compound at this condition. The complicated behavior of Mo and Me was reconfirmed in the present calculations.

\section{Post-Irradiation Examination}

In order to understand the behavior of FPs and actinides, we performed post-irradiation examinations (PIE) on the high-burnup mixed oxide (MOX) fuel. The microstructure and element distribution of the fuel surface were analyzed by using the electron probe micro analyzer (EPMA) and the optical microscope. The fuel contained $0.4 \% \mathrm{Am}$ and was irradiated at the experimental fast reactor JOYO. Irradiation of the fuel spanned 1019.33 effective full power days. The 


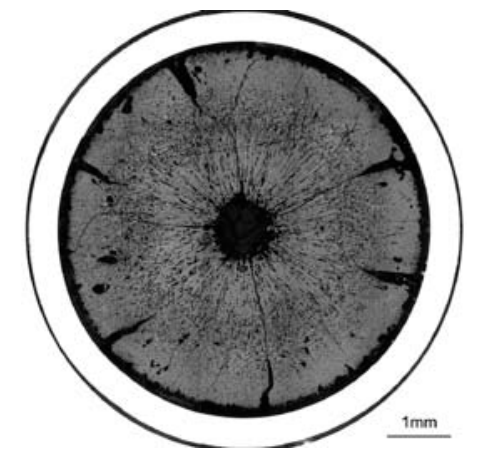

Fig. 3 Ceramograph of the whole surface area of the irradiated MOX fuel pellet

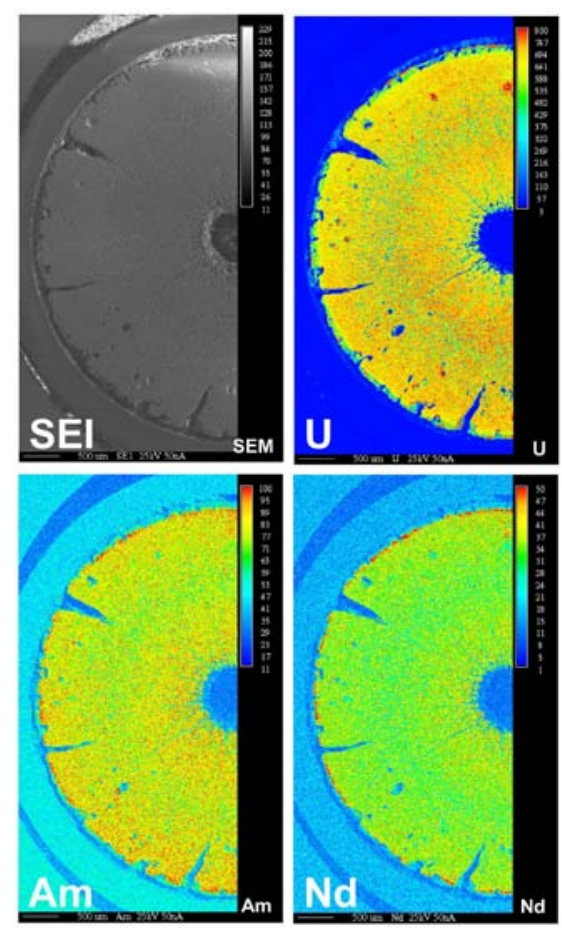

Fig. 4 EPMA mapping images (SEI, U, Am, and Nd) of the irradiated MOX fuel pellet

maximum linear heating rate was approximately $38 \mathrm{~kW} / \mathrm{m}$, that was recorded in the first stage of the irradiation period. The peak burn-up reached around $144 \mathrm{GWd} / \mathrm{t}$.

Figure 3 shows the ceramograph of the whole surface area of the irradiated MOX fuel pellet. The central void formation was clearly observed.

Figure 4 shows the EPMA images of the fuel, in which SEI means secondary electron image. It was observed that U and Am as well as Nd distributed throughout the fuel pellet. Some FPs, for example rare earth elements and minor actinides (MAs) co-dissolved into the fuel matrix and formed a solid solution of (U,Pu,MAs,FPs) $\mathrm{O}_{2}$.

On the other hand, some FPs such as $\mathrm{Zr}$ and $\mathrm{Ba}$ did not dissolve into the fuel matrix but precipitated as oxide inclusions known as the gray phase. Figure 5 shows the EPMA mapping results of $\mathrm{Zr}$ and $\mathrm{Ba}$ for the same fuel pellet. It was observed that $\mathrm{Zr}$ and $\mathrm{Ba}$ coprecipitated in the middle area of

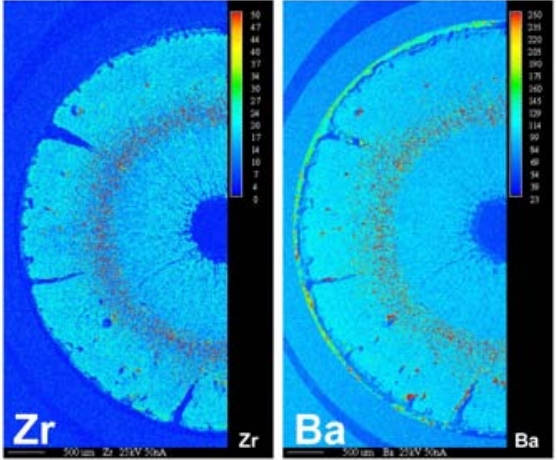

Fig. 5 EPMA mapping images $(\mathrm{Zr}, \mathrm{Ba})$ of the irradiated MOX fuel pellet

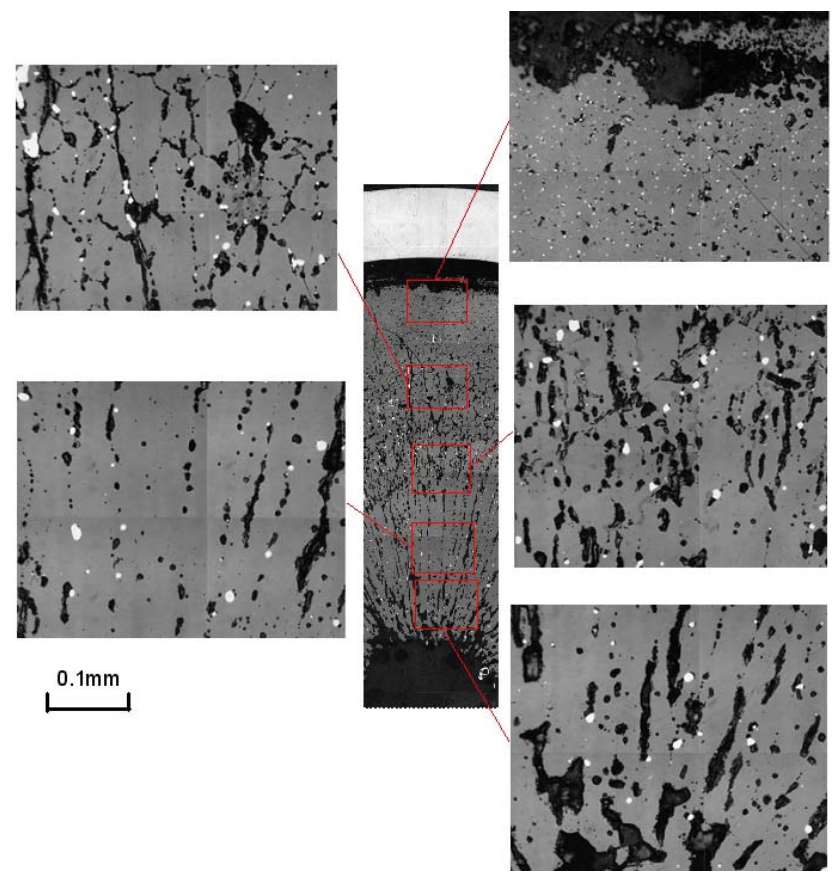

Fig. 6 Optical micrographs of the irradiated MOX fuel pellet
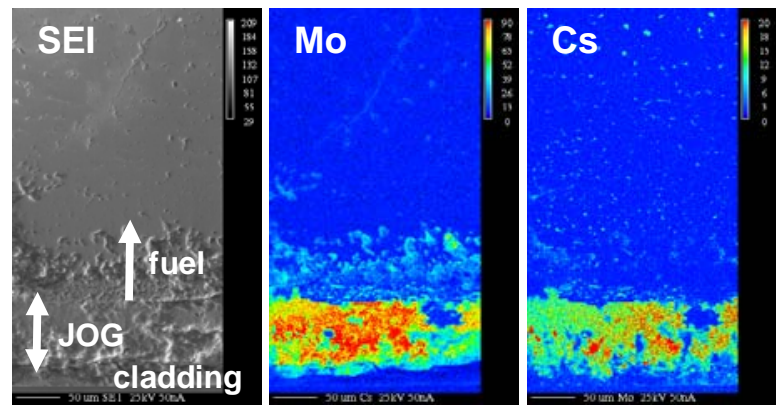

Fig. 7 EPMA mapping images (SEI, Cs, and Mo) of the irradiated MOX fuel pellet (outer region); JOG means joint oxide gain

the fuel pellet; and perhaps they would form a multiple oxide, such as $\mathrm{BaZrO}_{3}$. This result was consistent with the thermodynamic calculation results reported in the previous section, even though the calculation was performed at 1,273 K (temperature at the middle area of the fuel pellet was around $1,800 \mathrm{~K})$. 
Furthermore, some FPs such as Mo and the platinum group elements did not dissolve into the fuel matrix but formed metallic inclusions. Figure 6 shows the optical micrographs for the same fuel pellet. The white metallic inclusions composed of Mo-Tc-Ru-Rh-Pd alloys can be observed. Almost all Mo existed as the white metallic inclusions, but some of it co-existed with Cs on the outside region of the fuel, as shown in Fig. 7. Perhaps, Mo and Cs would form complex oxides (JOG: joint oxide gain) such as $\mathrm{Cs}_{2} \mathrm{MoO}_{4}$, in this area.

\section{Summary}

In order to understand the chemical states of the FPs and actinides in the irradiated oxide fuels, the thermodynamic equilibrium calculation as well as the PIE was performed on the high-burnup mixed oxide (MOX) fuel. In the PIE, the element distributions on the fuel were analyzed by using the EPMA and the optical microscope. Although the free energy of each solution phase was treated by the ideal solution model, the present calculation results were validity compared with the PIE results.

In addition, the thermodynamic calculation was performed on the fuel with $100 \mathrm{GWd} / \mathrm{t}$, whereas the PIE was performed on the fuel with $144 \mathrm{GWd} / \mathrm{t}$. This burnup difference would lead to the difference in the ratio/amount of the elements in the system. Nevertheless, the calculation results were consistent with the PIE results. It was found that the multi-component and -phase thermodynamic equilibrium calculation between the fuel and FPs system would be an effective tool for understanding the phase equilibria of the irradiated oxide fuels.

\section{Acknowledgment}

Present study includes the result of "Study on the physical properties of nuclear fuels with multi phase system: Toward establishment of the closed cycle system with low-decontaminated oxide fuel" entrusted to Osaka University by the Ministry of Education, Culture, Sports, Science and Technology of Japan (MEXT).

\section{References}

1) H. Kleykamp, "The chemical state of the fission products in oxide fuels,” J. Nucl. Mater., 131, 221-246 (1985).

2) H. Kleykamp, J. O. Paschoal, R. Pejsab, F. Thümmler, "Composition and structure of fission product precipitates in irradiated oxide fuels: Correlation with phase studies in the Mo-Ru-Rh-Pd and BaO-UO $\mathrm{U}_{2}-\mathrm{ZrO}_{2}-\mathrm{MoO}_{2}$ Systems," J. Nucl. Mater., 130, 426-433 (1985).

3) G. Eriksson, K. Hack, "ChemSage-A computer program for the calculation of complex chemical equilibria," Metall. Mater. Trans., B21, 1013-1023 (1990).

4) M. J. Bell, ORIGEN-2 Code, ORNL-TM4397, Oak Ridge National Laboratories (ORNL) (1973).

5) P. G. Lucuta, R. A. Verral, Hj. Matzke, B. J. Palmer, "Microstructural features of SIMFUEL - Simulated high-burnup $\mathrm{UO}_{2}$-based nuclear fuel,” J. Nucl. Mater., 178, 48-60 (1991). 